\title{
The Silverway Guidewire: An Observational Study on Successful Crossing when a Conventional J-tip Wire has failed
}

\author{
Van Den Buijs DMF ${ }^{1}$, Poels EM${ }^{1}$, Ferdinande $\mathbf{B}^{1}$, Cottens $D^{1}$, Vrolix $\mathbf{M}^{1}$, Holvoet $\mathbf{W}^{1}$, Ameloot $\mathbf{K}^{1}$, Dens $\mathbf{J}^{1^{*}}$ \\ ${ }^{1}$ Department of Cardiology, Hospital Oost-Limburg, Genk, Belgium.
}

*Corresponding Author: Jo Dens, MD, PhD, Department of Cardiology Ziekenhuis Oost-Limburg Schiepse Bos 6, 3600 Genk, Belgium.

Received Date: December 07, 2021; Accepted Date: December 15, 2021; Published Date: January 03,2022

Citation: Van Den Buijs DMF, Poels EM, Ferdinande B,Cottens D,Vrolix M. et all (2022). The Silverway Guidewire: An Observational Study on Successful Crossing when a Conventional J-tip Wire has failed. J. Clinical Cardiology and Cardiovascular Interventions, 5(2); DOI:10.31579/2641$0419 / 239$

Copyright: (c) 2022 Jo Dens, This is an open-access article distributed under the terms of the Creative Commons Attribution License, which permits unrestricted use, distribution, and reproduction in any medium, provided the original author and source are credited.

Abstract

Aim: The aim of this observational study was to evaluate the Silverway guidewire [Asahi Intecc Co.] that is designed to guide catheters during cardiac catheterization towards the aortic valve when the standard J-tip guidewire fails because of anatomical anomalies.

Materials and Methods: A total of 50 consecutive patients, in which the Silverway guidewire was used, were analyzed: procedural characteristics, such as anatomical challenges, crossing of the vessel and deliverability of the catheters were prospectively collected. This sample size was considered reasonable to describe the success, because this was the first observational study on the performance of the Silverway guidewire.

Results: In the majority of procedures, transradial access was used (47 cases; $94 \%$ ). The Silverway guidewire was able to cross the vessel in $98 \%$ and to deliver catheters in $92 \%$ of patients. Most anatomical challenges occurred at the radial artery level (39 cases). No clinical important complications occurred after use of the Silverway guidewire.

Conclusion: The Silverway guidewire is highly successful in overcoming anatomical obstacles without vascular complications during cardiac catheterization when the J-tip guidewire fails to cross the vascular anatomy.

Key words: cardiac catheterization; vascular anatomy; tortuous anatomy; silverway guidewire

\section{Introduction}

To date, radial approach is the preferred access site for cardiac catheterization. [1] Compared with the femoral approach, radial access has significant reduction in mortality, major bleeding complications, major adverse cardiac events (MACE) and vascular complications, and lowers mortality in patients with ST-segment elevation myocardial infarction (STEMI). [2,3]

Though infrequent, vascular complications still remain, including radial artery spasm $(15 \%)$, perforation $(<1 \%)$, thrombotic occlusion $(1-10 \%)$, hematoma, pseudoaneurysm $(0.03 \%-0.09 \%)$, arteriovenous fistula $(0 \%$ $0.08 \%)$ and compartment syndrome $(0.004 \%)$ and can be associated with significant morbidity, in rare cases requiring surgical intervention. [4] The presence of radial artery spasm, tortuous anatomy or artery anomalies, can give rise to complications when a guidewire has to be crossed and may prolong procedure time or cross-over of access site. [4,5] Also, anomalies in the course from femoral access to the aortic valve occur and need to be overcome.

Once radial access is obtained, a regular J-tip guidewire (Spring wire) is advanced towards the aortic valve followed by a diagnostic or guiding catheter. If the J-tip guidewire encounters any resistance while traversing the arm, fluoroscopy is used to diagnose the problem. [4] When tortuosity or spasm is present, the operator can switch to a hydrophilic guidewire (Polymer wire). [6,7] This is a Nitinol guidewire covered with a hydrophilic polymer coating. It has higher lubricity for better vessel access and lesion crossing. However, challenges encountered with a Polymer wire are low torque transmission and less support compared to a Spring wire because of the Nitinol core. Furthermore, the high lubricity might cause easier entry into side branches and can cause a dissection or perforation. $[5,8,9]$

Theoretically, Asahi's newest Silverway guidewire (Spring coil guidewire) is designed to overcome these problems by introducing a 
double coil structure at the tip, a hybrid coating design and hybrid shaft design with ACT ONE (Asahi Cable Tube ONE) on the proximal shaft.
ACT ONE is a hollow wire rope that is wrapped around to form the outer wire (Figure 1).

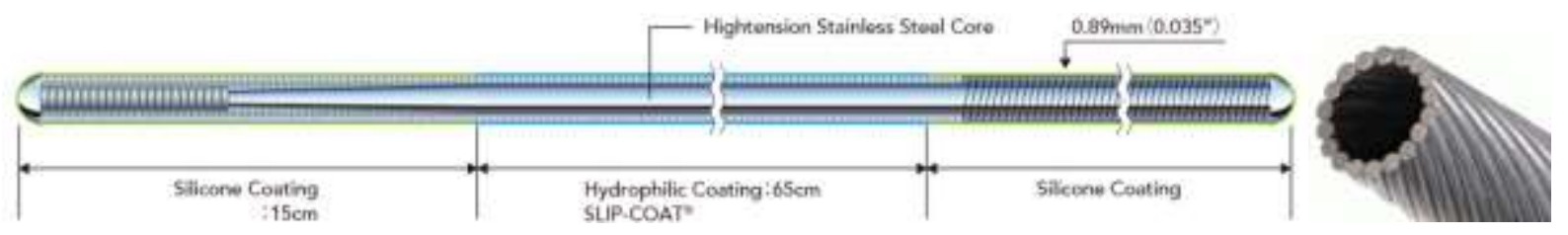

Figure 1: The structure of the Silverway guidewire (left), ACT ONE (right). Figures reproduced with permission of Asahi Intecc CO.

The combination of all these new technologies should incorporate good deliverability, torque transmission and safety. [10]

However, no data exist on clinical use of the Silverway guidewire. Therefore, the aim of this observational study was to evaluate the Silverway guidewire when the standard J-tip guidewire failed to cross because of anatomical anomalies.

\section{Materials and Methods}

The Silverway guidewire was used in 50 consecutive patients after resistance has been met with the standard J-tip guidewire. A sample size calculation was not applicable because this was the first observational study. This sample size was considered reasonable to describe the success of the Silverway guidewire when the standard J-tip wire failed.

Post-procedural worksheets were prospectively completed and included access puncture site, catheter use with French size, targeted coronary artery, the anatomical challenge or other challenges, if the Silverway crossed the vessel and/or delivered the catheter, additional tools and techniques used to deliver the catheter, need to change access site, use of a third guidewire and if any complications occurred.

It was not an obligation to routinely perform an arteriogram to visualize the anatomical challenge or post-procedure. If a local arteriogram was performed and a radial artery loop was visible, it was defined as the presence of a full $360^{\circ}$ loop of the radial artery distal to the bifurcation of the brachial artery. [6] Radial artery spasm was defined as documentation of spasm on the arteriogram and inability to advance the guidewire requiring use of vasodilators and other techniques.
More than one anatomical challenge could have been present and were reported.

Clinically relevant complications, such as bleeding or limb ischemia, both associated with prolonged hospitalization, were reported.

All categorical variables were analyzed and expressed as percentages. Descriptive statistic methods were used.

\section{Results}

A total of 50 patients underwent a cardiac catheterization with the use of a Silverway guidewire between July 2021 and November 2021.

In the majority of the procedures initially a right radial approach was used (42 patients; $84 \%$ ). In 5 patients (10\%) the left radial approach was used at start and in 3 patients $(6 \%)$ an initial femoral access was obtained.

A diagnostic catheter was used in 41 patients (82\%), a guiding catheter in 7 patients (14\%) and in 2 patients (4\%) it was not recorded. In the majority of procedures, a 6 French catheter was used (42 patients; 84\%).

Main anatomical challenges for which the standard J-tip guidewire was not able to deliver the catheter were radial loops (18 cases) and tortuosity (18 cases) and subclavian artery tortuosity (10 cases). Other challenges are summarized in Table 1 . In 14 patients more than 1 anatomical challenge was present.

\begin{tabular}{|l|l|l|}
\hline Characteristic & & Number of cases (\%) \\
\hline Access site & Right radial & $42(84 \%)$ \\
\cline { 2 - 3 } & Left radial & $5(10 \%)$ \\
\cline { 2 - 3 } & Right femoral & $3(6 \%)$ \\
\hline \multirow{4}{*}{$\begin{array}{l}\text { uspe of catheter } \\
\text { Size of catheter }\end{array}$} & Diagnostic catheter & $41(82 \%)$ \\
\cline { 2 - 3 } & Guiding catheter & $7(14 \%)$ \\
\cline { 2 - 3 } & Unknown & $2(4 \%)$ \\
\cline { 2 - 3 } & F French & $7(14 \%)$ \\
\cline { 2 - 3 } challenge & 6 French & $42(84 \%)$ \\
\cline { 2 - 3 } & Radial loops & $1(2 \%)$ \\
\cline { 2 - 3 } & Radial artery tortuosity & 18 \\
\cline { 2 - 3 } & Brachial loops & 18 \\
\cline { 2 - 3 } & Subclavian artery tortuosity & 10 \\
\cline { 2 - 3 } & Subclavian calcification & 1 \\
\cline { 2 - 3 } & Femoral tortuosity & 3 \\
\cline { 2 - 3 } & Femoral calcification & 1 \\
\hline
\end{tabular}




\begin{tabular}{|c|c|c|}
\hline & Resistance in distal radial artery & 1 \\
\hline & Radial artery spasm & 3 \\
\hline & Axillary artery tortuosity & 3 \\
\hline & Extremely tortuous ascending aorta & 1 \\
\hline & Unknown & 1 \\
\hline & Double anatomical challenge & 14 \\
\hline \multirow{3}{*}{$\begin{array}{l}\text { Procedural } \\
\text { challenge }\end{array}$} & Tip does not cross & $46(92 \%)$ \\
\hline & Spasm & $2(4 \%)$ \\
\hline & Unknown & $2(4 \%)$ \\
\hline \multirow{2}{*}{$\begin{array}{l}\text { Change access } \\
\text { site }\end{array}$} & Yes & $0(0 \%)$ \\
\hline & No & $50(100 \%)$ \\
\hline \multirow{2}{*}{$\begin{array}{l}\text { Silverway } \\
\text { crossed the vessel }\end{array}$} & Yes & $49(98 \%)$ \\
\hline & No & $1(2 \%)$ \\
\hline \multirow{2}{*}{$\begin{array}{l}\text { Silverway } \\
\text { delivered the } \\
\text { catheter }\end{array}$} & Yes & $46(92 \%)$ \\
\hline & No & $4(8 \%)$ \\
\hline \multirow{3}{*}{$\begin{array}{l}\text { Additional tools } \\
\text { to deliver } \\
\text { catheter }\end{array}$} & PCI wire (Sion, Asahi) & $1(2 \%)$ \\
\hline & Radifocus (Terumo) guidewire & $2(4 \%)$ \\
\hline & Change of access site & $1(2 \%)$ \\
\hline \multirow{2}{*}{$\begin{array}{l}\text { Catheter } \\
\text { delivered after } \\
\text { additional tools }\end{array}$} & Yes & $4(8 \%)$ \\
\hline & No & $0(0 \%)$ \\
\hline \multirow[t]{2}{*}{ Complications } & Yes & $0(0 \%)$ \\
\hline & No & $50(100 \%)$ \\
\hline
\end{tabular}

Table 1: Procedure characteristics.

$\mathrm{RCA}=$ right coronary artery. $\mathrm{LCA}=$ left coronary artery. $\mathrm{LIMA}=$ left internal mammary artery. $\mathrm{PCI}=$ percutaneous coronary intervention In none of the patients access site was changed after the J-wire was not able to deliver the catheter. Using the Silverway guidewire, the vessel was crossed in 49 patients (98\%) and the catheter was able to be delivered to the aortic valve in 46 patients (92\%). In all femoral cases (3 cases; 6\%) the Silverway was able to deliver the catheter (Figure 2).

50 patients with anatomical challenge and failure of J-wire to deliver catheter

Use of Silverway guidewire

49 (98\%) patients
Silverway crossed the vessel
Silverway guidew
46 (92\%) patients
Silverway delivered the catheter

1 patient

- Resistance in distal artery,

- Use of PCl wire --> vessel crossed
1 patient

- Radial loops and axillary tortuosity

- Terumo guidewire delivered the catheter 1 patient

- Extreme tortuous ascending aorta

- Change access to left radial $\rightarrow$ catheter delivered

1 patient

- Radial and subclavian tortuosity

- Terumo guidewire delivered the catheter 
The case where the Silverway was not able to cross the vessel involved the challenge of resistance in the distal radial artery. In 3 cases, catheters could not be delivered to the aortic valve after successful crossing with the Silverway. These patients had a radial loop and axillary artery tortuosity $(\mathrm{n}=1)$, an extremely tortuous ascending aorta $(n=1)$, and the last case challenged radial and subclavian artery tortuosity $(\mathrm{n}=1)$.

In the single patient where the Silverway was unable to cross the vessel, a PCI wire (Sion; Asahi Intecc Co.) was used and eventually the vessel was crossed. In the patients where the Silverway was unable to deliver the catheter to the aortic valve, additional tools were used to deliver the catheter, such as the use of a Radifocus (Terumo) guidewire (2 patients; $4 \%$ ) and change of access site (1 patient; 2\%). In all patients eventually, the targeted coronary artery was reached.

No clinically relevant complications after use of the Silverway guidewire were reported. There was no screening for radial artery occlusion post procedure.

\section{Discussion}

This is the first observational study which describes the use of the Silverway guidewire to guide a catheter to the aortic valve during cardiac catheterization after failure of the conventional J-tip wire and it shows to be highly successful. In $98 \%$ of the cases the Silverway guidewire was able to cross the vessel and in $92 \%$ of the cases the Silverway guidewire was able to deliver the catheter to the aortic valve, where the standard J-tip guidewire failed. The cases where the Silverway failed to deliver the catheter, experienced either more than one anatomical challenge or an extreme challenge, which demonstrates the complexity of the case.

Although we did not perform a systematic post-procedural radial arteriogram, no clinically relevant complications occurred with the use of the Silverway guidewire.

A total of 47 patients (94\%) received a cardiac catheterization by radial approach. Anatomical obstacles occurred mostly at the radial artery level (39 cases). Radial artery tortuosity and loops together covered 36 cases in comparison to spasm in only 3 cases (6\%). In literature both higher (12\%) [11] and lower incidences of spasm are described (2.8\%). [12] This difference can be explained by underreporting because of missing arteriogram, variations in definitions and prophylactic vasodilatory spasmolytic therapy. [4]

In only one case (2\%) it was necessary to change access site after use of the Silverway guidewire. This case comprised an extremely tortuous ascending aorta where the Silverway guidewire was not able to reach the ascending aorta and delivered not enough support to visualize the targeted coronary artery. Eventually, access site was changed to the left radial artery and the targeted coronary artery was visualized.

In 2 cases, where the targeted coronary artery was not reached after use of the Silverway guidewire, the Radifocus guidewire by Terumo was used. The targeted coronary artery was eventually reached with guidance of this Radifocus guidewire (a coated Polymer wire). It might be that the Terumo in these cases was more flexible to cross the tortuosity.

Usually, when resistance is encountered advancing a J-tip guidewire, fluoroscopy can be used. If the J-tip guidewire will not advance, a coated guidewire (Radifocus or Glidewire (Terumo)) can be maneuvered up the arm. [6] The risk of using a coated guidewire is that is can easily penetrate side branches, which can cause perforation. [13] If resistance is felt, fluoroscopy is advised. [5] Once the guidewire has reached the shoulder, fluoroscopy is used to ensure safe passage of the guidewire and catheter to the aortic root. If spasm is the anatomical challenge, additional intra-arterial antispastic medication can be administered and/or the use of a smaller catheter (such as 4 or 5 French). [4] When this fails, a technique called 'balloon-assisted tracking' can be helpful, particularly for radial loops. $[9,14,15]$ When everything fails, change access site.

Major study limitations include the small sample size and a lack of routinely performed arteriograms to visualize the actual anatomical challenge. The presented data should therefore be considered as exploratory, nevertheless highly promising and should set the scene for randomized studies comparing Radifocus and Silverway guidewires.

\section{Conclusion}

The Silverway guidewire is highly successful in crossing anatomical obstacles during cardiac catheterization with radial and femoral access, when the J-tip guidewire fails.

Further research is needed to evaluate feasibility of the Silverway guidewire and to compare different guidewires for success, feasibility and workability.

\section{References}

1. Neumann F.J., Sousa-Uva M., Ahlsson A., Alfonso F., Banning A.P., et al. 2018 ESC/EACTS Guidelines on myocardial revascularization. The Task Force on myocardial revascularization of the European Society of Cardiology (ESC) and European Association for Cardio-Thoracic Surgery (EACTS) Giornale Italiano di Cardiologia. 2019;20: S1-S61.

2. Bertrand OF, Bélisle P, Joyal D, et al. Comparison of transradial and femoral approaches for percutaneous coronary interventions: a systematic review and hierarchical Bayesian meta-analysis. Am Heart J. 2012;163: 632-648.

3. Joyal D, Bertrand OF, Rinfret S, Shimony A, Eisenberg MJ. Meta-analysis of ten trials on the effectiveness of the radial versus the femoral approach in primary percutaneous coronary intervention. Am J Cardiol 2012;109: 813-818.

4. Sandoval Y., Bell M.R., Gulati R. Transradial artery access complications. Circ Cardiovasc Interv. 2019;12.

5. Caputo RP, Tremmel JA, Rao S, et al. Transradial arterial access for coronary and peripheral procedures: executive summary by the transradial committee of the SCAI. Catheter Cardiovasc Interv. 2011;78(6):823-839.

6. Bertrand OF, Rao SV, Pancholy S, et al. Transradial approach for coronary angiography and interventions: results of the first international transradial practice survey. JACC Cardiovasc Interv. 2010;3(10):1022-1031.

7. Bertrand $\mathrm{O}$, de Palma R, Meerkin D. Vascular access. Percutaneous Interventional Cardiovascular Medicine: The EAPCI Textbook 2012, vol I, part 1 (online edition).

8. Niazi K, Farooqi F, Devireddy C. Comparison of hydrophilic Guidewires Used in Endovascular Procedures. Journal of Invasive Cardiology. 2009; 21:397-400.

9. Tóth GG, Yamane M, Heyndrickx GR. How to select a guidewire: technical features and key characteristics. Heart 2015;101:645-652.

10. Lo TS, Nolan J, Fountzopoulos E, et al. Radial artery anomaly and its influence on transradial coronary procedural outcome. Heart (British Cardiac Society) 2009;95(5):410-415.

11. Basavarajaiah S, Brown A, Naganuma T, Gajendragadkar P, McCormick L, West N. Should Technical and Anatomical Difficulties Discourage Operators from Embarking on Transradial Access for Percutaneous Coronary Intervention? J Invasive Cardiol. 2018;30: 341-347. 
12. Brilakis E. Manual of Percutaneous Coronary Interventions. Chapter 5 - Coronary and graft engagement. Academic Press 2021; 71-95.

13. Kern MJ. The Cardiac Catheterization Handbook $6^{\text {th }}$ edition. Elsevier 2016; 64-65.

14. Hildick-Smith DJR, Walsh JT, Lowe MD, et al. Transradial coronary angiography in patients with contraindications to the femoral approach: an analysis of 500 cases. Catheter Cardiovasc Interv. 2004;61(1):60-66.
15. Gasparini GL, Sanz Sanchez J, Gagnor A, et al. Effectiveness of the "new rope coil" composite core Suoh 0.3 guidewire in the management of coronary artery dissections. Catheter Cardiovasc Interv. 2020; 96(4):E462-E466
Ready to submit your research? Choose Auctores and benefit from:

$>$ fast, convenient online submission

$>$ rigorous peer review by experienced research in your field

$>$ rapid publication on acceptance

$>$ authors retain copyrights

$>$ unique DOI for all articles

$>$ immediate, unrestricted online access

At Auctores, research is always in progress.

Learn more https://auctoresonline.org/journals/clinical-cardiology-andcardiovascular-interventions 